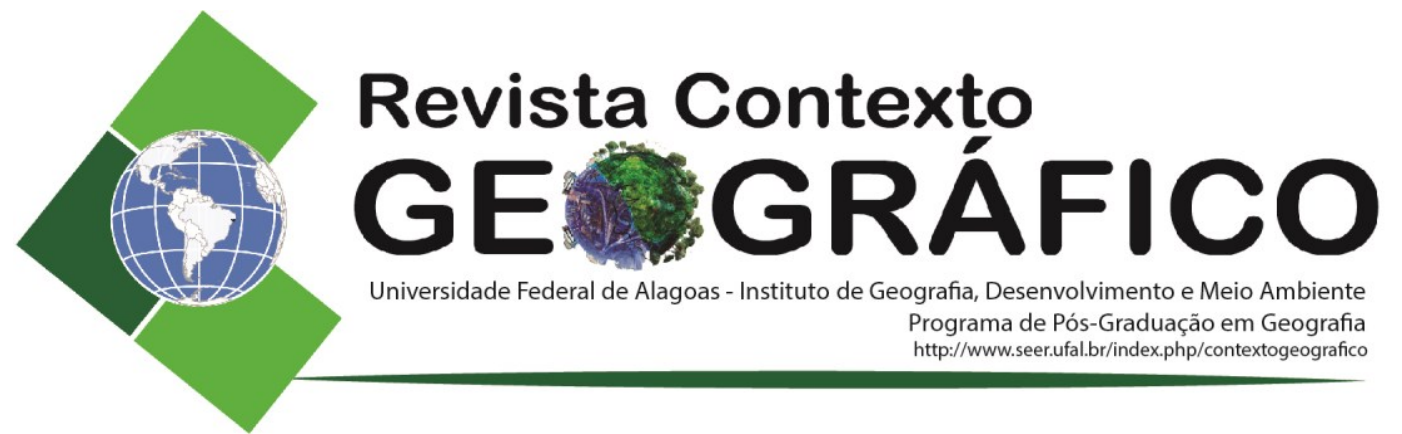

\title{
TERRITÓRIO, CRÉDITO E DESENVOLVIMENTO: O BANCO DO NORDESTE DO BRASIL NA INTERFACE DOS DOIS CIRCUITOS DA ECONOMIA URBANA EM ALAGOAS
}

\author{
Diêgo Rodrigues da Silva \\ Mestre em Geografia pelo Programa de Pós-Graduação em Geografia do Centro de Ciências \\ Humanas, Letras e Artes da Universidade Federal do Rio Grande do Norte, Natal, RN, Brasil \\ diego.uneal@gmail.com \\ Dhiego Antonio de Medeiros \\ Professor da Universidade Estadual de Alagoas, Campus V, União dos Palmares, AL, Brasil \\ dhiego.medeiros@uneal.edu.br
}

\begin{abstract}
RESUMO - O artigo ora apresentado tem por objetivo explicar a inserção recente do Banco do Nordeste do Brasil (BNB) no circuito inferior da economia urbana alagoana, através de programas de crédito especialmente direcionados às camadas sociais de menor renda. O trabalho está fundamentado sobretudo na teoria dos dois circuitos da economia urbana, desenvolvida por Santos ([1975] 2008), analisada à luz dos novos elementos do período atual, a exemplo da desburocratização do acesso ao crédito, da difusão das redes bancárias e da configuração da rede urbana alagoana. A análise mostrou que a capilaridade do crédito no circuito inferior se estrutura em uma peculiar divisão do trabalho bancário, na qual, em uma mesma operação de crédito, se verifica a ação de agentes dos dois circuitos econômicos, tanto na oferta quanto na obtenção do crédito. Sob o prisma teórico em pauta, o processo investigado evidencia um maior imbricamento das conexões entre os circuitos, em uma relação hierárquica e complexa, cujos efeitos sobre os mais pobres vêm sendo pouco investigados.
\end{abstract}

Palavras-chave: Capilaridade; Microcrédito; Circuito inferior.

\section{TERRITORY, CREDIT AND DEVELOPMENT: THE BANCO DO NORDESTE DO BRASIL IN THE INTERFACE OF THE TWO CIRCUITS OF THE URBAN ECONOMY IN ALAGOAS}

\begin{abstract}
The article introduced has the objetive explain the recently insertion of Banco do Nordeste do Brasil (BNB) in the lower circuit of urbain alagoan economy, through credit programs mainly directioned to social layers of low income. The work is reasoned principally on the theory of two cicuits of the urbain economy, developed by Santos ([1975] 2008), analyzed according to the new elements of the current period, such as the disbureaucratization of access to credit, the difusion in the bank networks and the configuration alagoana urban network. The analisys demonstrated that the capillarity of credit in the lower circuit is structured on a peculiar division of banking work, in which, in a same credit operation, the action of agents of both economic circuits is verified, both in the offer, and in the credit obtaining. Under the theoretical prism on schedule, the investigative proccess evidences a larger connection between the circuits, on a hierarchial and complex relationship, whose effects on the poorest people have been little researched.
\end{abstract}

Keywords: Capillarity; Microcredit; Lower circuit.

\section{INTRODUÇÃO}

Marcado historicamente por seu caráter seletivo, o aparelho bancário tem buscado, especialmente a partir do processo de reestruturação bancária iniciado na década de 1990, uma ampliação crescente do seu alcance territorial e também social. Através de seus programas de 
microcrédito, o Banco do Nordeste do Brasil (BNB) integra esse movimento recente de financeirização do circuito inferior. Sob o argumento da inclusão financeira, o BNB lidera largamente a oferta de microcrédito no estado.

Trilhando nesse sentido, uma das grandes críticas à redução das desigualdades via aparelho bancário está no fato de que este, devido à sua forma burocrática de organização, comumente limitava-se ao financiamento de atividades normatizadas, capazes de oferecer garantias legais de cumprimento das normas estabelecidas pelos bancos. Emerge daí, portanto, a grande contradição que norteia a abordagem desse estudo, fundada nas concepções de Milton Santos ([2001] 2006 e [1996] 2009) sobre os "usos do território" e na teoria dos "dois circuitos da economia urbana nos países subdesenvolvidos", apresentada pelo mesmo autor no seu livro "O Espaço Dividido" ([1975] 2008).

É, portanto, a partir desse prisma, que se tomou como objeto de análise o BNB que, mesmo representando um tipo de atividade geralmente ligada ao circuito superior, tem se destacado no sistema financeiro pela forma como perpassou os níveis da estrutura social nordestina, financiando atividades do circuito inferior da economia urbana. No estado de Alagoas esse processo se revela complexo e desafiador, tendo em vista a diversidade de elementos que contribuem para a formação de nexos entre os circuitos.

\section{USOS DO TERRITÓRIO PELO BNB: DO CONHECIMENTO DO TERRITÓRIO, AO FINANCIAMENTO DOS CIRCUITOS PRODUTIVOS ESTRATÉGICOS}

A crise econômica vivenciada no mundo a partir de 1929, com duras sequelas nos anos seguintes, desencadeou grandes transformações na economia brasileira, cujos alicerces fundamentavam-se fortemente no seu caráter primário-exportador. Essa dependência do setor externo potencializou os efeitos da crise no País. A nova realidade exigiu do Estado brasileiro, estratégias que visassem garantir a sustentabilidade de seu modelo econômico e manter a competitividade de seu principal produto - notadamente o café - no mercado, nos anos de instabilidade que sucederam a crise. Entretanto, "a baixa brusca no preço internacional do café e a falência do sistema de conversibilidade acarretaram a queda do valor externo da moeda" (FURTADO, [1959] 2000, p. 200).

Assim, o insucesso das tentativas do governo fez com que parte apreciável da renda nacional permanecesse dependente da conjuntura econômica mundial, o que, dada a instabilidade política e econômica vivenciada no período, inibia as possibilidades de crescimento econômico do país. Ademais, não se tratava apenas de prover as bases necessárias ao abastecimento de um mercado externo abalado pelo prolongamento da crise, mas também de fazer isso de modo a assegurar, paralelamente, o suprimento da demanda interna de produtos. Tal problema ia se tornando insustentável, ao se considerar os desníveis de renda acrescidos pela adoção de um esquema dual da divisão de trabalho centrado no desequilíbrio entre as atividades mais lucrativas, em sua maioria, ligadas a um mercado externo já em declínio, e as atividades de subsistência voltadas para o consumo interno. Os frequentes períodos de crise e/ou guerras, acarretaram um progressivo aumento das desigualdades socioeconômicas no país, conduzindo a um impasse, o qual o Estado brasileiro, anos mais tarde, teve que enfrentar.

Em resposta ao desafio e encabeçando uma tendência geral seguida pelos demais países da América Latina, o Brasil programou uma nova estratégia econômica pautada na substituição de importações. Nesse sentido, "o período do pós-guerra caracterizou-se, de modo geral, por uma expansão e mudança contínua na estrutura industrial brasileira" (TAVARES, [1972] 1981, p. 70), que ampliou seu leque de produtos ao passo que reduzia o número de importações. Contudo, a abertura do mercado interno para a expansão do meio técnico-científico não veio acompanhada de uma melhora 
nos organismos de articulação econômica que foram, como asseverou Furtado, (apud TAVARES, [1972] 1981, p. 160) "falhando em criar um mercado socialmente integrado e orientando o mesmo para a satisfação da demanda diversificada dos grupos de rendas mais altas", a saber, pela notória centralização dos investimentos no Sudeste e no Sul do país, que detinham instaladas no seu território a maior parcela da renda nacional. Somado a isso, percebe-se que a existência de uma base técnica já montada contribuiu para a formação de um mercado interno que deu origem à região "concentrada", (SANTOS, [2001] 2006, p. 140). Em contrapartida, esse processo trouxe à luz um território nacional profundamente fragmentado.

Nesse mesmo período, intensificavam-se na Europa os debates sobre os desequilíbrios regionais, que se aprofundavam nos países após a Segunda Guerra Mundial. O aumento das preocupações com as disparidades regionais conduziu à formação dos bancos de desenvolvimento nesses países, tais como o Banco Internacional de Reconstrução e Desenvolvimento (BIRD), que assim como tantos outros criados na Europa ocidental, tinham como objetivo primeiro, induzir o desenvolvimento econômico das regiões arrasadas pelos efeitos da guerra.

Entretanto, no Brasil, a ausência de áreas contínuas dotadas de infraestrutura impedia a formação de um mercado interno integrado, que permitisse a implementação de um dinamismo econômico mais intenso, capaz de promover o escoamento da produção industrial. É em grande parte em função disso que o Estado brasileiro acaba "por aumentar também a tomada de consciência acerca das desigualdades regionais que se gestavam" (CONTEL, 2011, p. 70). Ganha, portanto, força nos debates sobre o funcionamento da economia nacional, as preocupações com o que Araújo (2005) chamou de "fratura da nação", combatida em todo o discurso de Celso Furtado, que chamava a atenção quanto ao papel dos bancos, que se concentravam nas metrópoles mas agiam como mecanismos de drenagem das áreas deprimidas para os centros mais dinâmicos do país. Assim, é inspirado no modelo europeu, mas com contornos bem específicos, conforme citado anteriormente, que tem origem no Brasil, após a segunda metade do século XX, um ambicioso plano de integração nacional, que tinha no desenvolvimento regional o seu principal alicerce. Alguns eventos trazidos por Wilson Cano (2000) evidenciam bem esse processo:

\begin{abstract}
Em 1953 fora criada a SPVEA (Superintendência do Plano de Valorização Econômica da Amazônia), transformada em 1966 na Sudam (Superintendência para o Desenvolvimento da Amazônia). Em 1956, era criada a SPVERFSP (Superintendência do Plano de Valorização Econômica da Região da Fronteira Sudoeste do País), transformada em 1967 na Sudesul; em 1961, criava-se a Codeco (Comissão de Desenvolvimento do CentroOeste), em 1967 transformada na Sudeco, e, finalmente, também em 1967, criava-se a Suframa, instituindo-se a Zona Franca de Manaus. (CANO, 2000, p. 105).
\end{abstract}

No caso do Nordeste brasileiro, a estagnação econômica era creditada muito mais à vulnerabilidade às secas do que propriamente à herança de estruturas econômicas defeituosas, haja vista as intempéries climáticas que castigavam ciclicamente a região. Aliás, essa possuía uma economia fortemente movida pelas atividades agropecuárias, o que dificultava, por conseguinte, $\mathrm{o}$ desenvolvimento econômico na área do polígono das secas. Isso se apresentava como um grande problema para o Nordeste, uma vez que o polígono das secas representava $62,7 \%$ do território. Tendo em vista essa realidade, foram criados pelo Governo Federal, organismos institucionais que tinham como primeira finalidade o combate às secas, como o Departamento Nacional de Obras Contra as Secas (DENOCS), em 1945, a Comissão do Vale do São Francisco (CVSF) e a Companhia Hidrelétrica do São Francisco (CHESF), ambas em 1948.

A drenagem de recursos pelos bancos comerciais fez aumentar a preocupação do governo em equilibrar a organização financeira do território. Para Contel (2011, p. 75): "A existência de atores públicos em regiões menos desenvolvidas de qualquer território contribui para evitar a concentração 
de capitais nas cidades e nas regiões mais dinâmicas desses mesmos espaços”. Buscava-se assim, canalizar os mecanismos de captação e irrigação de recursos dos bancos convencionais em favor do crescimento econômico de uma área específica.

É sob a égide desenvolvimentista exercida no governo Vargas, que tem origem o Banco do Nordeste do Brasil S/A em 1952, pela Lei $\mathrm{n}^{\circ}$ 1649. A criação do primeiro banco de desenvolvimento do país marcava uma significativa mudança na forma de perceber o problema nordestino, reconhecendo a importância das finanças no novo contexto histórico que se iniciava e atribuindo aos bancos um papel central para o funcionamento e reprodução das demais atividades econômicas no território que, na ausência de bancos locais, protagonizavam a uma "fuga de capitais" para a região concentrada.

Desde a sua criação, o BNB já se constitui banco múltiplo, podendo exercer todas as funções permitidas aos bancos comerciais e de desenvolvimento. Contudo, ao contrário das demais instituições bancárias que operam com o chamado "perverse flow of credit" (MYNT, 1965b, apud SANTOS, [1975] 2008, p. 108), escoando o crédito de regiões deprimidas para regiões mais dinâmicas, o BNB surge com o objetivo de financiar principalmente o desenvolvimento econômico dos "espaços opacos" do território açambarcado por sua jurisdição.

Todavia, para melhor entender o funcionamento do $\mathrm{BNB}$ e a relação que este foi tendo com o território ao longo de sua história, impõe-se a necessidade de uma periodização que leve em conta a questão dos usos do território. Esse tipo de análise geográfica é fundamental para a compreensão do objeto em estudo, ao passo que permite entender a sucessão dos meios geográficos que se entrelaçam à sua trajetória, ancorado na superposição de técnicas, no arcabouço normativo e ideológico por assim dizer, nos diversos fluxos, que implicam transformações financeiras, entre outros aspectos determinantes para compreender a atuação BNB. Especialmente por que:

Cada periodização se caracteriza por extensões diversas de formas de uso, marcadas por manifestações particulares interligadas que envolvem juntas e obedecem a princípios gerais, como a história particular e a história global, o comportamento do Estado e da nação (ou nações) e, certamente, as feições regionais. (SANTOS, [2001] 2006, p. 20).

De início, pode-se admitir a existência de, pelo menos, três períodos distintos que antecedem o período atual, marcados por diferentes formas de uso do território. O primeiro período (19521961) é caracterizado pelo fortalecimento da sua estrutura organizacional, pelo planejamento econômico e conhecimento do território. O segundo período (1962-1974) configura uma transição para uma fase posterior da sua história, com a perda de recursos estáveis e pela busca de novas fontes de recursos para a instalação de próteses que permitissem uma maior fluidez das atividades. Já a terceira fase (1975-1994) é marcada por uma postura mais agressiva do BNB no mercado, através do financiamento de atividades econômicas estratégicas para o crescimento econômico nordestino.

Apesar de ter sido oficialmente originado em 1952, o BNB só passou a atuar efetivamente a partir de 1954, quando inaugurou sua primeira agência com sede em Fortaleza - CE. Na ocasião, 2/3 dos seus recursos provinham do chamado Fundo das Secas, que representava 1\% das receitas tributárias da União. Para Francisco de Oliveira ([1977] 1981, p. 94), essa forma de intervenção estatal dificultava a redefinição do esquema de reprodução do capital no Nordeste. Aliás, não é por acaso que este autor acredita que "o Banco do Nordeste do Brasil viverá amarrado aos recursos orçamentários, sendo, portanto, ainda uma forma rudimentar de transferência de imposto", sobretudo porque limitava seu raio de ação à área do polígono das secas.

No período marcado pela emergência da ação das finanças no território, o conhecimento constitui-se numa ferramenta muito preciosa e precisa. Quando sob o domínio dos atores 
hegemônicos, o conhecimento do território constitui um importante recurso (SANTOS, [1975] 2008), garantia de satisfação de seus interesses particulares. No caso do $\mathrm{BNB}$, o acesso ao conhecimento da realidade regional fazia-se igualmente indispensável para um banco que tem como preocupação básica "executar uma política de desenvolvimento ágil e seletiva, capaz de contribuir de forma decisiva para a superação dos desafios e para a construção de um padrão de vida compatível com os recursos, potencialidades e oportunidades da Região" (BNB, 2012). Criado nos moldes de um banco especializado na dinâmica econômica regional, o BNB sente, assim, a necessidade de ampliar os conhecimentos sobre o funcionamento da economia do Nordeste, o que, dada a escassez de informações sobre a região, motivou a criação de organismos técnicos de estudos e pesquisas, com o objetivo de sistematizar as ações do banco nos anos seguintes à sua criação.

No mesmo ano é inaugurado, como previsto no Decreto-Lei que deu origem ao BNB, o Escritório Técnico de Estudos do Nordeste (ETENE), cujo papel consistia em elaborar estudos macroeconômicos e setoriais sobre a economia nordestina. Ao longo do tempo o ETENE destacou-se por montar uma considerável base de dados sobre as especificidades da economia nordestina. Segundo Fernando Mota (apud SANTOS; GOIS, 2012, p. 113) "a organização do Etene foi, sem dúvida, o pré-requisito indispensável ao estabelecimento de uma política regional no Nordeste". Desde a sua criação, o ETENE constituiu-se numa importante ferramenta, mapeando áreas de investimento e respaldando cientificamente a atuação do BNB.

Em 1956, a pedido do BNB, é implantado o Grupo de Trabalho para o Desenvolvimento do Nordeste (GTDN) coordenado pelo economista Celso Furtado, que intensificou os estudos sobre as dificuldades e potencialidades da região, estabelecendo uma política de desenvolvimento especializada no Nordeste. O GTDN destacou-se, sobretudo, em 1959, quando publicou o relatório denominado "Uma Política de Desenvolvimento Econômico para o Nordeste", um dos mais importantes e precisos documentos já feitos sobre a economia nordestina, que ajudou o BNB a planejar suas ações nos anos seguintes. Esse órgão posteriormente foi transformado no Conselho de Desenvolvimento do Nordeste (CODENO). Ligado ao movimento cepalino, o GTDN teve papel fundamental na criação da Superintendência de Desenvolvimento do Nordeste (SUDENE) em 1959, que passou a cumprir um papel de extrema importância nas diretrizes estratégicas da instituição.

Uma das principais dificuldades enfrentadas pelo $\mathrm{BNB}$, era a falta de funcionários especializados, dada a escassez de profissionais qualificados e ao fato de que os funcionários do banco só poderiam ser contratados mediante concurso público, como previsto no Art. $25^{\circ}$ da lei de sua criação. Assim, "o BNB passou a investir na formação de pessoal especializado, promovendo, entre 1955 a 1957 vários cursos e treinamentos para especialistas em desenvolvimento econômico" (CARDOSO, 2006, p. 113). Em 1961, "o Banco do Nordeste e a Universidade Federal do Ceará elaboraram o projeto de criação do Centro de Treinamento em Desenvolvimento Econômico Regional (CETREDE), com o propósito de qualificar mão de obra local para suprir a industrialização emergente" (BNB, 2012). Ao término desse ano, o banco já tinha linhas de crédito especializadas definidas, sendo: $38 \%$ em crédito geral, $25 \%$ em crédito rural e $37 \%$ em crédito industrial.

Observa-se nesse período que as estratégias de desenvolvimento econômico arquitetadas pelo Banco do Nordeste direcionaram-se, sobretudo no plano organizacional, na construção de uma aprofundada base de informações, que lhe permitiu elaborar numerosos relatórios sobre lugares e setores de atividades em desenvolvimento potencial no Nordeste, permitindo um uso "just-intime" dos seus recursos materiais e humanos. Portanto, o conhecimento do território e as ações coordenadas marcaram a atuação do Banco do Nordeste nesse período. 
O movimento de renovação da materialidade no território brasileiro exercia grande influência nas estratégias de atuação do BNB. As mudanças normativas instituídas pelo Governo Federal que, motivado por esse mesmo processo, buscava diversificar o parque industrial nordestino, também causaram grandes transformações nas políticas praticadas pela instituição bancária. A substituição do Fundo das Secas pelo sistema de incentivos fiscais 34/18, pelo Art. $4^{\circ}$ da Lei $n^{\circ}$ 3.995 de 1961, apontava para essa realidade. Essa substituição, contudo, representou uma significativa perda de recursos estáveis para o banco, que passou a buscar fontes alternativas, visando ampliar seu patrimônio líquido numa segunda fase da sua história, que antecedeu uma postura mais ativa no mercado, como se verificará mais adiante. A existência de fontes estáveis de capital fazia-se fundamental para o Banco do Nordeste, segundo Ribeiro (1996, apud CARDOSO, 2006, p. 112) "devido ser o BNB uma instituição de desenvolvimento, cujos objetivos estão intimamente relacionados com a existência de recursos".

Verifica-se, nessa passagem, o predomínio do crédito geral, responsável por $44 \%$ da carteira do banco, que buscava, dessa forma, maximizar os lucros e assegurar seu funcionamento em uma época de grande instabilidade política e econômica. Percebe-se ainda, a continuidade de eventos característicos do período de planejamento econômico, como a criação do Fundo de Desenvolvimento Científico e Tecnológico (FUNDECI), em 1971. É possível identificar também elementos de transição para uma nova estratégia de intervenção que se iniciava. $\mathrm{O}$ crédito para infraestrutura, que antes representava menos de $1 \%$ de suas aplicações, passou a ocupar $11 \%$ da carteira de crédito do banco evidenciando uma grande preocupação com instalação de novas próteses que garantissem a fluidez da dinâmica econômica que emergia com o processo de industrialização. A criação do Fundo de Desenvolvimento Urbano do Nordeste (FUNDURBANO) em 1972, para o melhoramento da infraestrutura nos grandes centros regionais, aponta para esse sentido.

Iniciava-se assim, um processo de preparação para a expansão da indústria que, motivada pelo mecanismo 34/18, estava em expansão no Nordeste. Nesse período, as atividades industriais representavam apenas $15 \%$ dos financiamentos do banco enquanto as atividades agrícolas ocupavam $30 \%$ do total. Isso se deve ao predomínio de uma economia ainda centrada na produção agropecuária. Ao todo, as aplicações do Banco do Nordeste em relação ao sistema bancário regional, chegavam aos $21,2 \%$, capilarizados no território por meio das 70 agências instaladas até o período.

A necessidade de financiamento do meio técnico-científico levou o governo, em 1974, a substituir o sistema 34/18, incapaz de atender a crescente demanda de crédito do setor industrial, pelo Fundo de investimento do Nordeste (FINOR). A criação do FINOR em detrimento da extinção do mecanismo 34/18 representou, ainda, uma importante perda de recursos, obrigando o BNB a ampliar suas fontes de captação, de modo a garantir a sustentabilidade de suas ações. Inicia-se a partir desse período, uma forma de uso do território marcada pelo dinamismo econômico, drenagem de recursos e direcionamento dos investimentos, orientado pelo potencial produtivo da cada atividade na sua área de atuação.

De fato, apesar dos bancos de desenvolvimento se caracterizarem, de maneira geral, por oferecer crédito produtivo, captar recursos é tão importante para uma instituição bancária quanto executar empréstimos e financiamentos, seja qual for o tipo de serviço oferecido. De sorte que, como seus recursos oscilavam muito, sendo muitas vezes insuficientes em relação às necessidades de investimentos, o banco sente-se obrigado a recorrer a seus próprios organismos financeiros em favor das lógicas capitalistas que assegurem seu funcionamento.

Verifica-se a partir de então, um expressivo aumento da rede de agências, orientado para a captação de repasses do público, inclusive com a abertura de agências nos estados de São Paulo, 
Rio de Janeiro e para o Distrito Federal. Além disso, o banco inaugura linhas de crédito especializadas em atividades econômicas na Espanha, em Taiwan e no Japão, visando drenar recursos dessas áreas e redirecioná-los para o financiamento de atividades econômicas estratégicas na região Nordeste, ligadas à segurança nacional:

\footnotetext{
Iniciaram-se os financiamentos no âmbito do POLONORDESTE (Programa de Desenvolvimento de Áreas Integradas do Nordeste) e, no ano seguinte, começam a ser operacionalizados o Programa Especial de Apoio ao Desenvolvimento da Região Semiárida do Nordeste (Projeto Sertanejo) e o Programa Nacional do Álcool (PROÁLCOOL). (BNB, 2012).
}

O Crédito industrial foi a grande preocupação do BNB nesse período. Consideradas "atividades mais produtivas", as atividades industriais representavam a mais promissora fonte de investimentos da instituição. Cabe destacar a necessidade que se tinha em obter um rápido e expressivo resultado econômico, dado o contexto de afirmação política e ideológica do Capitalismo frente ao Socialismo. Assim, em 1975 é instituído o Programa de Crédito Industrial Suplementar (PCIS), que visava simplificar o acesso ao crédito a pequenas indústrias. No mesmo ano é inaugurado o Departamento de crédito Industrial (CARIN). Além disso, são lançados o Departamento de Operações Internacionais (DEPIN), que lançava o banco no mercado de câmbio e, em 1986, o Plano de Captação de recursos (Placar). Nesse caminhar, novas medidas foram tomadas, no sentido de fortalecer sua estrutura financeira, ameaçada pela constante perda de recursos. Dentre essas medidas destacam-se: "o lançamento da caderneta de poupança, a criação da mesa de câmbio, a emissão de certificados de depósito bancário-CDB, em 1988, e a operacionalização de fundos de curto prazo e renda fixa, cartão de crédito" (CARDOSO, 2006, p. 115).

Novas iniciativas de redução das disparidades regionais, após esforços do ETENE, resultaram na aprovação pelo Governo Federal do Fundo Constitucional de Financiamento do Nordeste (FNE), capítulo especial na história do banco. Esse fundo previa a destinação de 3\% das receitas totais da União para as regiões Norte, Nordeste e Centro-Oeste, dividido entre elas por critérios populacionais, o que conferiu ao Nordeste o valor de $1,8 \%$ das receitas totais a serem operacionalizadas pelo Banco do Nordeste através de seus programas. O FNE tornou-se ao longo do tempo a principal fonte de recursos do banco e abriu caminho para a forma de intervenção econômica mais intensa desde a sua criação.

Esses eventos, portanto, alteram os conteúdos financeiros do território nordestino, ao passo que inserem uma nova dinâmica econômica encabeçada pelo setor secundário, visto pelo banco como o polo dinamizador da economia, sendo responsável, portanto, por $36 \%$ da sua carteira de crédito em 1994, além de outros $27 \%$ para o fortalecimento dos sistemas de engenharia que davam suporte ao funcionamento do setor. Em contrapartida o crédito para atividades agrícolas cai para $23 \%$ e o crédito geral para apenas $14 \%$. Com efeito, na medida em que o Nordeste aumentava sua participação na renda nacional, tendo entre 1960 e 1990 praticamente sextuplicado seu PIB, aumentavam-se também as disparidades de renda na região, dada a ausência de incentivos a atividades de pouco mérito econômico. A expansão da rede de agências que atingiu 181 unidades fixas e o aumento da drenagem de recursos de outras áreas, contribuíram para que o Nordeste alcançasse taxas elevadas de crescimento econômico, em detrimento, porém, do aumento das disparidades sociais internas. AGENTES DE CRÉDITO DO BANCO DO NORDESTE DO BRASIL: UM TRAÇO DE
UNIÃO ENTRE OS CIRCUITOS DA ECONOMIA URBANA 
Os avanços técnicos adquiridos a partir do último decênio do século $\mathrm{XX}$, sobretudo, no que concerne às técnicas da informação, impulsionaram uma nova racionalidade ao território. Tanto os territórios dotados de elevada densidade técnica quanto aqueles desprovidos de tais recursos, passam a serem alvos de uma espessa rede de drenagem, controlada de maneira instantânea e coordenada, a partir lugares cada vez mais longínquos e, portanto, alheios às lógicas de funcionamento locais. A difusão do meio técnico-científico e agora informacional, intensificou os fluxos através da expansão das redes, montando um complexo esquema de reprodução do capital, marcado pela velocidade com que opera e pela interdependência das atividades que compõem o processo produtivo. $\mathrm{O}$ que aparentemente parece definir uma expressão da integração territorial, na verdade constitui um poderoso esquema de drenagem e irrigação de recursos, que tem no aparelho bancário o combustível que move as demais atividades.

Nesse sentido, observa-se que, no Brasil, a pulverização das diversas atividades econômicas motivou grandes transformações na legislação no que tange ao funcionamento das instituições bancárias que, diante disso, passaram por um processo de liberalizações normativas, no sentido de diversificar seus serviços e atender a demanda crescente de crédito. Partindo desse princípio, torna-se justificável o desmembramento da atividade bancária que, fazendo uso dos avanços técnicos, passou a contar com novos mecanismos de ação, como bem mostra Contel (2011, p. 221):

É aprofundada a utilização dos Postos de Atendimento Bancário (PAB's) e dos "Caixas Automáticos" ou (ATM's); mas são também criadas novas formas de acessibilidade aos serviços bancários, dadas pela expansão do uso de "correspondentes bancários" e de novos canais eletrônicos no Território.

As normatizações instituídas pelo Banco Central contribuíram para a instalação de novas formas geográficas porém, como se sabe, tais formas não são apenas formas, mas "formas-conteúdo" (SANTOS, [1985] 2008) e sendo, portanto, dotadas de funcionalidade, implicaram transformações na dinâmica financeira do território. Esse processo, entretanto, tornou o uso do território ainda mais seletivo, na medida em que os investimentos são atraídos pelas atividades que oferecem o maior retorno econômico. Isso tornou mais nítido, o contraste existente entre as áreas "luminosas" e "opacas" do território.

Todavia, não foram apenas os bancos comerciais que se beneficiaram da difusão do meio técnicocientífico informacional. Nesse mesmo período, mais precisamente no ano de 1995, inicia-se no Banco do Nordeste o maior processo de mudança já realizado na instituição, inspirado pelo sucesso das políticas instituídas por um grupo de empresários que assumiram o governo no estado do Ceará, o BNB promove intensas modificações na sua estrutura organizacional. Esse processo tinha como principais características:

O redesenho do processo de concessão de crédito, que assegurou maior agilidade nas operações, e com a reorientação da rede de agências, que passam a ter modelos diferenciados em função do mercado. [...] Amplia-se a rede de comunicação de dados e são adquiridos microcomputadores de última geração, passando o Banco a contar, praticamente, com um micro por funcionário (BNB, 2012).

Além disso, inspirado na experiência do Grameen Bank, em Bangladesh, o BNB implanta uma estratégia de desenvolvimento local, pautada na concessão de microcrédito produtivo e orientado a pequenas atividades econômicas que, incapazes de se adaptarem às modernas formas de concessão ao crédito, não recebiam incentivos financeiros que lhes permitissem expandir seu negócio. Conhecido como o banqueiro dos pobres, Yunus, o idealizador do projeto, ficou convencido que "os pobres são merecedores de confiança, pois pagam seus pequenos empréstimos destinados a atividades produtivas" e implantou um mecanismo de crédito baseado na formação de "grupos solidários". O aval para a obtenção do crédito por meio da união voluntária e espontânea de pessoas 
interessadas em obter o crédito, assumindo a responsabilidade conjunta no pagamento das prestações.

Cabe destacar que, no caso do BNB, a modernização das redes de comunicação, foi fator fundamental para a elaboração de uma nova estratégia de atuação voltada para o financiamento de atividades não normatizadas, levando o crédito bancário para uma importante parcela da sociedade, antes desprovida de serviços dessa natureza, sem abrir mão dos mecanismos de captação instituídos ao longo do tempo. No entanto, a aproximação do crédito bancário a um grupo de atividades que não oferecem garantias oficiais que de pagamento, só foi possível com o surgimento de mecanismos, até então, atípicos ao Sistema Bancário Tradicional.

Deve-se salientar ainda, que o novo plano de ação inaugurado pelo BNB, constitui-se num importante passo para a redução do fosso que separa os "dois circuitos da economia". Compete aqui, aliás, fazer uma breve distinção entre eles, segundo os critérios de nível técnico e de organização, estabelecidos por Santos ([1975] 2008, p. 43). O circuito superior - grosso modo - consiste em um conjunto de atividades modernas, que utiliza uma tecnologia importada e de alto nível, seu funcionamento depende de formas burocráticas de organização e é movido pelo "capital intensivo", fornecido pelo sistema bancário. Já o circuito inferior, constitui um imitativo do circuito moderno, e tem na força de trabalho uma compensação para a falta de capital, já que o nível organizacional de suas atividades não permite o acesso ao crédito bancário.

É evidente que um expressivo e ambicioso processo de reorganização administrativa tal qual foi proposto nas novas diretrizes da instituição, leve também em conta algumas mudanças estruturais essenciais à elaboração de um modelo mais abrangente e inclusivo. O novo modelo deveria ser capaz de alcançar pequenas atividades, consideradas formais ou informais como: carpintarias, salões de beleza, vendedores ambulantes, sapatarias, oficinas mecânicas, marcenarias, mercadinhos, artesanatos, lanchonetes, borracharias, alfaiatarias, feirantes, padeiros, açougueiros, etc. Enfim, as atividades citadas neste item como público-alvo das novas linhas de crédito inauguradas pela instituição, constituem elementos que ajudam a compor o circuito inferior da economia, cujo funcionamento, conforme assinalado anteriormente, foge às normas impostas pelo moderno sistema bancário nacional.

Além disso, tendo em vista a impossibilidade financeira de o banco fixar-se fisicamente em todos os municípios da região, criava-se uma grande lacuna entre a necessidade de assistir de forma mais intensa as áreas mais desprovidas de investimento e as reais possibilidades de fazê-lo. Visto, ainda, que grande número dos municípios nordestinos não possuía uma infraestrutura básica capaz de oferecer as condições mínimas necessárias à instalação de uma agência.

Em todo caso, como intervir de maneira eficaz no desenvolvimento daqueles lugares cuja taxa de retorno financeiro é mercadologicamente inferior aos investimentos efetuados e, prover simultaneamente, as bases econômicas e materiais, necessárias à reprodução permanente desse processo? Em longo prazo é impensável fazer-se presente em todos esses locais, sem que os organismos que se beneficiam da presença da instituição assegurem seus altos custos de permanência, de modo a garantir a reprodução das operações creditícias naquele local.

Pensando nisso, em 1996 o BNB introduz, em caráter inovador, o Programa Agentes de Desenvolvimento, um tipo de intermediário móvel da instituição. Os agentes são funcionários terceirizados pelo banco, sua função é disseminar pessoalmente programas e serviços preestabelecidos pelo banco nas localidades onde ele não conseguiu se instalar fisicamente. A criação dos agentes de crédito provocou uma reorientação e redução do número de agências após esse período, passando de 181 unidades em 1994, para 172 em 1996. 
Com o novo desenho organizacional, o BNB consegue, através desses intermediários móveis, capilarizar sua topologia a mais de 1955 municípios inseridos na sua área de atuação, estendendo inclusive, sua presença ao Norte dos estados de Minas Gerais e do Espírito Santo. Embora caracterize uma relativa precarização do serviço bancário, a atuação dos agentes torna-se imprescindível face à nova realidade. Sendo eles menos dependentes de fixos geográficos, cria-se uma nova artéria, através da qual o BNB estabelece um contato mais direto e local com os espaços opacos do território.

A atuação dos agentes de desenvolvimento, contudo, não garantia sozinha a passagem do crédito ao circuito inferior da economia. Os valores e as taxas de juros antes cobrados pelo banco faziam-se inacessíveis à parcela de pobres incluída no público-alvo do BNB. Tal dificuldade motivou a criação de novas linhas de crédito, com o objetivo de amoldar seus mecanismos creditícios às especificidades do mercado. Assim, em 1997 é criado o Programa de Microcrédito Produtivo e Orientado Crediamigo, visando desburocratizar o acesso ao crédito às atividades do circuito inferior da economia, com taxas de juros menores do que as encontradas no mercado.

Outro grande problema enfrentado era o desconhecimento da dinâmica econômica local por parte dos agentes de desenvolvimento, que criavam distorções no processo de articulação da demanda de crédito e de seleção das propostas a serem encaminhadas à agência. O resultado foram os elevados índices de inadimplência registrados nos primeiros anos. Essa dificuldade levou à criação do Programa Farol do Desenvolvimento, um fórum de debates sobre a economia local, no intuito de aproximar as exigências do banco às necessidades e possibilidades dos clientes. $\mathrm{O}$ banco estabeleceu também um limite de inadimplência que, quando ultrapassado, determina o fim das suas ações naquele local.

Dessa forma, os presidentes de associações comunitárias que pretendem dispor dos serviços do $\mathrm{BNB}$, são chamados a participar periodicamente de reuniões que visam estabelecer um diálogo entre o banco e os microempreendedores, através da figura dos assessores de microcrédito. Os presidentes de associações passam a constituir peças-chave da relação que o banco estabelece com as atividades do circuito inferior, pois, o fato de residirem nas comunidades onde atuam e conhecerem a maioria dos clientes, cria uma nova possibilidade de identificar as pessoas e atividades mais propensas a honrar seus compromissos junto à instituição.

No ano de 2005, foi criado o Programa Agroamigo, com o propósito de capilarizar a oferta de crédito bancário às áreas rurais. Este programa mostra-se ainda mais adequado a intensificar os nexos financeiros entre banco e a agricultura familiar, devido ao ínfimo valor cobrado nas taxas de juros $(0,5 \%$ ao ano) e ao bônus de $25 \%$ de desconto por adimplência no valor do financiamento na área do polígono das secas. Apesar de todas as facilidades e benefícios que o programa oferece, o sucesso do Agroamigo é ainda mais dependente do trabalho dos presidentes de associações ao se considerar o perfil dos clientes do programa, em sua maioria composto de pessoas que não chegaram a concluir o ensino fundamental.

Os presidentes de associações, entendidos neste estudo como "agentes de microcrédito" apresentam algumas características particulares, que lhes permitem intermediar a passagem do crédito para $\mathrm{o}$ circuito inferior da economia. Uma pesquisa exploratória executada no município de Traipu - AL, que de acordo com o Censo Demográfico apresentado pelo IBGE (2010), constitui um dos municípios mais pobres do Brasil, buscou caracterizar esse agente de microcrédito. Observou-se então, que esses agentes se difundiram com muita rapidez em todo o município a partir da segunda metade da década de 1990. Além disso, conforme assinalado no item precedente, eles comumente integram as comunidades onde atuam o que facilita os conhecimentos sobre o mercado de clientes, geralmente composto de familiares, vizinhos, amigos e inclusive por ele próprio. 
Isso significa que esses agentes de microcrédito, quase sempre possuem uma atividade principal geralmente atrelada ao circuito inferior. Seu trabalho é divulgar nas comunidades, as linhas de crédito destinadas ao financiamento de atividades do circuito inferior, orientar e providenciar junto aos clientes a documentação exigida, efetuar cobranças de dívidas em atraso, além de marcar as visitas às comunidades junto ao assessor de crédito do banco. $\mathrm{O}$ baixo nível de complexidade de suas atividades como agente de crédito não exige dele um grau de escolaridade elevado. Desse modo, predominam entre esses agentes, os que cursaram no máximo até o nível médio de ensino. Apesar de não constituir uma atividade normatizada, no que se refere a intermediação do crédito, muitos agentes acabam recebendo do cliente, uma porcentagem (entre 5\% e 10\%) do valor do empréstimo.

Ao longo do tempo, o trabalho dos agentes de microcrédito foi se tornando cada vez mais indispensável ao banco, pois, conforme apresentado a seguir no Gráfico 1, se refletiu num progressivo aumento do número de operações, concomitante a uma considerável queda das taxas de inadimplência. Para os clientes o papel dos presidentes de associação tornou-se igualmente importante, pois eles passaram a ser responsáveis pela elaboração dos projetos, orientação sobre a documentação necessária, bem como sobre os procedimentos a serem tomados nas entrevistas com os funcionários do banco na hora da solicitação do recurso. Todavia, a falta de uma lei que normatize a atuação desses presidentes e regulamente seus direitos trabalhistas, limita sua atuação, uma vez que estes precisam dedicar parte apreciável de seu tempo a outras atividades que assegurem a sua subsistência, dificultando assim, a passagem do crédito para as atividades do circuito inferior.

Gráfico 1. Região Nordeste: Número de operações do Programa Agroamigo (2005-2011)

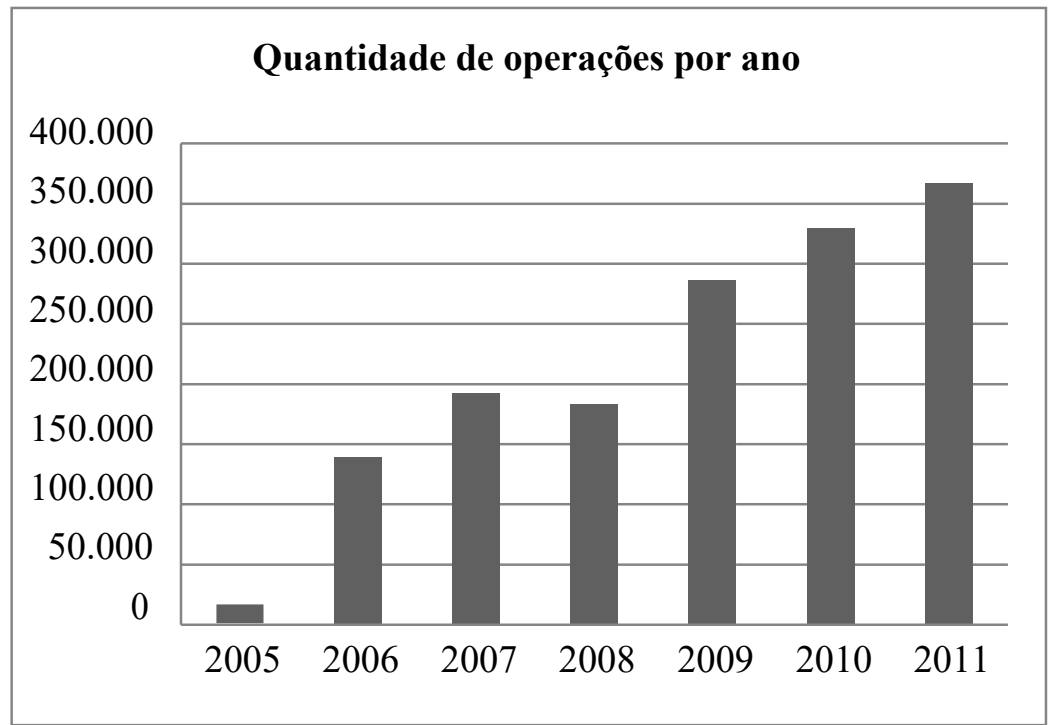

Fonte: BNB: Agroamigo - Relatório, 2011. Elaboração própria.

Apesar de prestar um importante serviço à instituição financeira, os presidentes de associações comunitárias, que trabalham como agentes de microcrédito, não possuem nenhum tipo de vínculo trabalhista oficializado com o banco, que se beneficia do serviço por eles prestado. Deve-se destacar ainda que grande parte desses intermediários financeiros compõe parte da grande parcela de pobres, que frequentemente recorrem ao banco para garantir a reprodução de suas atividades de subsistência. A compensação pelo serviço prestado à instituição financeira é, portanto, alcançada na parte de baixo da cadeia, ou seja, são os clientes que, por meio de repasses às associações ou aos próprios 
agentes, sustentam a atuação desses agentes, cujo esforço como parte fundamental da divisão do trabalho bancário é financeiramente, negligenciado pelo BNB.

Desse modo, o trabalho dos agentes de desenvolvimento em sintonia com a ação dos agentes de microcrédito cria nexos hierárquicos entre a atividade bancária e as atividades não normatizadas. Essas atividades, igualmente, constituem nexos entre os dois circuitos da economia, através de um esquema de distribuição de recursos via aparelho bancário, que contribui para nutrir as atividades do circuito inferior.

\section{AGENTES DE MICROCRÉDITO E A CAPILARIDADE DO BANCO DO NORDESTE DO BRASIL NO ESTADO DE ALAGOAS}

Muitos estudos acerca da atuação do aparelho bancário no período atual, frequentemente negligenciam o fato de que vários fatores que contribuem para o entendimento do problema em análise estão direta ou indiretamente ligados ao circuito inferior da economia, cuja dinâmica é mais difícil de empiricizar, dada a escassez de dados ao seu respeito. Dessa forma, são criadas distorções que acabam por comprometer o resultado final da investigação. Uma das grandes riquezas desse estudo repousa na possiblidade de compreender a forma como os dois circuitos estão dispostos no território para, a partir dessa análise, desenvolver uma leitura da divisão territorial do trabalho bancário, congruente com a realidade.

Enquanto a formação do circuito superior se faz diretamente proporcional ao nível funcional da cidade, a concentração de atividades do circuito inferior nas cidades não se dá nessa mesma lógica. Sua importância também varia em função do nível hierárquico da cidade na rede urbana, expandindo no sentido inverso da importância dos centros. Baseado nesses princípios, Santos ([1975] 2008, p. 358) elabora um esquema geral do alcance dos dois circuitos da economia urbana nos países subdesenvolvidos, inspirado na teoria dos lugares centrais de Walter Christaller, conforme pode ser visto na Figura 1. É evidente que, devido a grande concentração populacional, o circuito inferior concentre um volume maior de atividades nas cidades de escalão superior. Todavia, em termos proporcionais, a divisão do espaço pelos dois circuitos não se explica pela mesma lógica conforme se verifica.

Figura 1. Hexágono de Christaller modificado pela existência dos dois circuitos da economia urbana

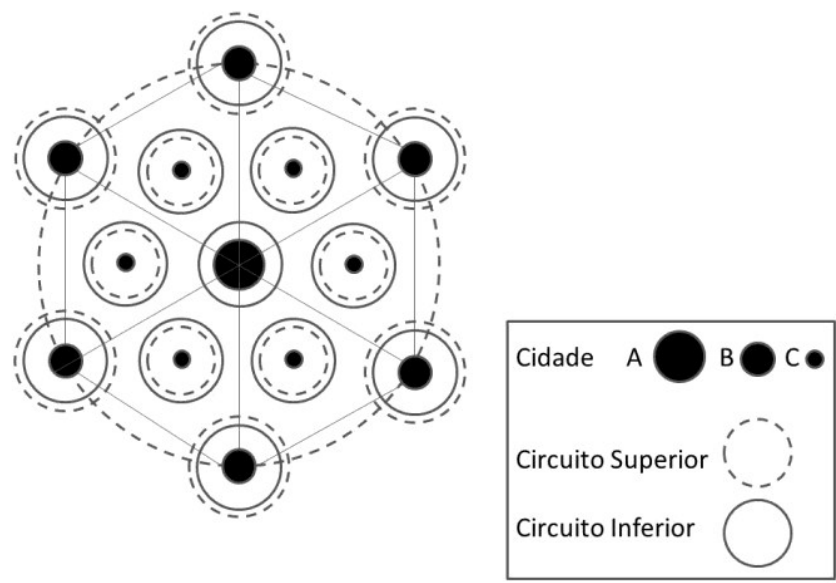

Fonte: Adaptado de Santos ([1975] 2008). 
Em Alagoas, a grande disparidade populacional e econômica entre os municípios do estado, indica com alguma nitidez a difusão diferencial dos dois circuitos em função do nível das cidades. O Mapa 1, apresentado no documento Regiões de Influência das Cidades (REGIC) e elaborado pelo Instituto Brasileiro de Geografia e Estatística (IBGE) no ano de 2007, revela o nível de influência exercido pelos centros regionais, através dos fluxos de bens, pessoas e serviços. Segundo o documento do REGIC, a hierarquia urbana brasileira pode ser classificada em dez níveis distintos que seguem a ordem decrescente de acordo com a importância das cidades no que se refere aos itens assinalados. Portanto é possível, a partir dos princípios estabelecidos por Santos ([1975] 2008) e dos dados do IBGE, geograficizar a existência dos dois circuitos no território alagoano.

Mapa 1. Alagoas: Regiões de influência das cidades (2007)

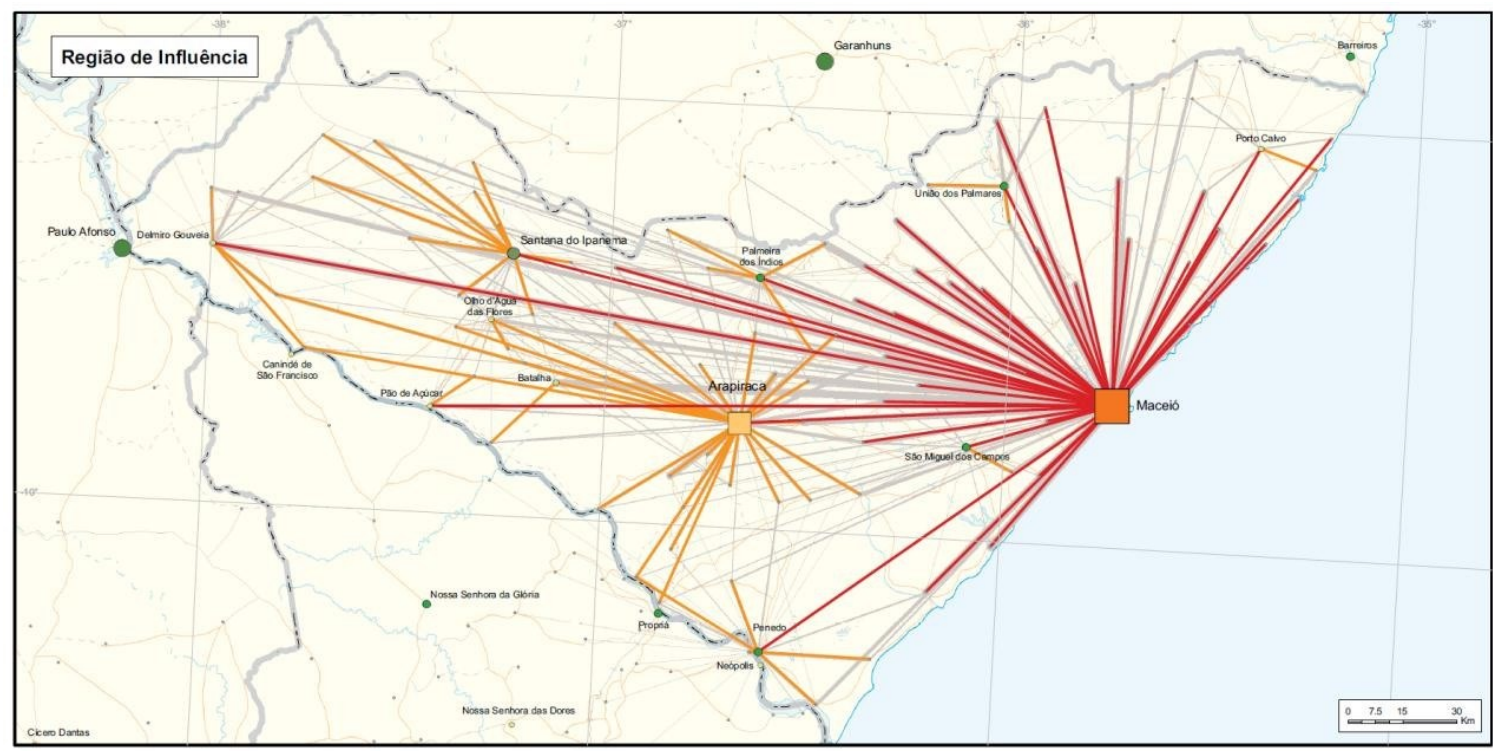

Fonte: IBGE (2007).

Como se pode verificar no mapa, o estado de Alagoas não apresenta todos os níveis urbanos descritos pelo REGIC. Não obstante, é grande a disparidade entre a região de influência da capital Maceió e os demais municípios do estado. No que concerne à difusão do circuito superior, essa cidade, enquanto capital regional " $\mathrm{A}$ " é a que dispõe de um circuito superior internamente mais consolidado, capaz de manter um dinamismo econômico interno e exercer simultaneamente influência sobre outras cidades. A cidade de Arapiraca como capital regional "C" também detém um circuito superior localmente articulado e capaz de exercer influência sobre várias cidades alagoanas, localizadas na Mesorregião Agreste do estado". Ainda assim, a precariedade das redes de transporte reduz o alcance desse circuito, que se difunde de maneira regressiva ao passo que se distancia dos centros em direção às cidades de escalão inferior.

Além dessas cidades, pode-se também identificar a existência de alguns centros de zona "A" como Palmeira dos Índios, Penedo, União dos Palmares, São Miguel dos Campos, Delmiro Gouveia e Santana do Ipanema, que possuem um circuito superior só parcialmente integrado, isto é, com atividades residuais, como bancos e algumas lojas de varejo. A concentração das indústrias, dos shoppings centers, das universidades, dos centros de saúde e de outras atividades modernas nas 
cidades de Maceió e Arapiraca, revelam a importância desses dois centros para o dinamismo econômico dessas outras cidades.

O restante do território alagoano caracteriza-se pelo predomínio de cidades locais, concebidas no estudo do IBGE como centros locais, que possuem pouca ou nenhuma centralidade em relação a outras cidades. Nesses municípios o circuito superior limita-se à existência de atividades isoladas, geralmente restritas ao setor bancário. É comum também a existência de atividades modernas que estão presas a esses locais para extrair matérias-primas, que normalmente não são encontradas em outras porções do território. Com efeito, nesses municípios, o alcance do circuito superior frequentemente fica circunscrito ao perímetro urbano. Além disso, grande parcela de suas atividades não está diretamente ligada à dinâmica local, o essencial de seus investimentos é manipulado de fora da cidade para onde vão seus lucros.

Já o circuito inferior encontra uma difusão generalizada em praticamente todos os 102 municípios do estado, haja vista a facilidade de instalação de pequenas atividades, pelo seu baixo custo de funcionamento e pela facilidade de gerir o pequeno negócio. Contudo, tendo em vista a escassez de uma base de dados mais específica ao seu respeito, seu alcance torna-se quase sempre difícil de precisar. Além disso, a existência de atividades sazonais dificulta ainda mais a definição de seus limites espaciais. Entretanto, sabe-se que seu alcance é frequentemente reduzido, graças à fragilidade da sua forma de organização usualmente restrita a um mercado próximo.

No que concerne aos centros regionais, o circuito inferior apresenta um grande número de atividades, reflexo da grande segmentação presente na sociedade urbana, maioria entre a população desses municípios. Todavia, seu alcance frequentemente é limitado pela existência de um circuito superior mais diverso, capaz de cobrir o conjunto de atividades necessárias ao consumo local. O raio de ação desse circuito comumente se assemelha aos limites administrativos do município e a reprodução de suas atividades depende, em sua maioria, das relações estabelecidas na cidade.

Nas cidades que são centros de zona "A", o alcance do circuito inferior fica circunscrito ao perímetro do município. O que muda, na verdade, é a sua importância devido à existência de um circuito superior incompleto e que, portanto, é incapaz de suprir as demandas básicas de consumo local. Mas é sobretudo nas cidades locais que o circuito inferior encontra um espaço central na economia do município. A falta de articulação local das atividades do circuito superior faz com que a reprodução das atividades do circuito inferior se confunda com a própria dinâmica econômica desses lugares. A abrangência do circuito inferior nesses municípios é socialmente maior do que o alcance do circuito superior, que se instala na cidade.

Por fim, é através das disparidades de renda e da divisão do trabalho, que os dois circuitos da economia traçam seus caminhos e definem sua função na economia dos municípios. Quando não estão vinculadas a políticas governamentais, as atividades do circuito superior apresentam-se frequentemente de forma seletiva no território, privilegiando aqueles mais capazes de oferecer um retorno ótimo dos recursos investidos. Como essa seletividade não se dá apenas no nível espacial, mas também social, proliferam-se atividades de pequena dimensão, responsáveis por garantir a subsistência de uma extensa parcela de pobres. Aliás, um fato comum a todos os municípios está no predomínio de uma sociedade com rendas muito baixas e, por conseguinte, muito dependente das atividades do circuito inferior. O estado aparece, portanto marcado pelo predomínio de atividades não regulamentadas, que apesar de não cobrirem uma grande área, se pulverizaram em diversas porções do espaço, representando o essencial da economia da maioria dos municípios alagoanos.

Para as agências bancárias, a difusão extremamente limitada do circuito superior, torna-se um grande obstáculo à penetração desse fixo geográfico no estado. Fica igualmente compreensível a razão pela qual a rede de agências bancárias encontra-se pouco capilarizada entre os municípios. Isso tem 
obrigado as instituições bancárias a adotarem outros mecanismos financeiros, como postos de atendimento bancário, correspondentes bancários e caixas automáticos, para levar os serviços bancários nos lugares onde as agências não conseguiram se instalar. Assim, face ao predomínio e à difusão generalizada de atividades do circuito inferior no estado, é que o BNB procura conectar seus mecanismos creditícios aos organismos financeiros que ajudam a compor o circuito inferior.

No estado de Alagoas, o Banco do Nordeste do Brasil dispõe de uma rede de agências pouco capilarizada, dispondo de apenas 11 unidades fixas distribuídas entre as cidades, cuja dinâmica econômica se enquadra em grande parte dos seus serviços bancários. Essas cidades caracterizam-se por exercer uma centralidade em relação aos municípios circunvizinhos que recorrem à agência quando necessitam de serviços bancários básicos como abertura de conta, saques, depósitos, etc. Além disso, a distribuição da sua rede de agências é ainda mais restrita do que a princípio aparenta, pois, em um estado que possui 102 municípios, só a capital Maceió detém para si três agências, enquanto as oito restantes são distribuídas entre os outros municípios conforme se verifica no Mapa 2.

Mapa 2. Alagoas: Rede de agências do Banco do Nordeste do Brasil (2012)

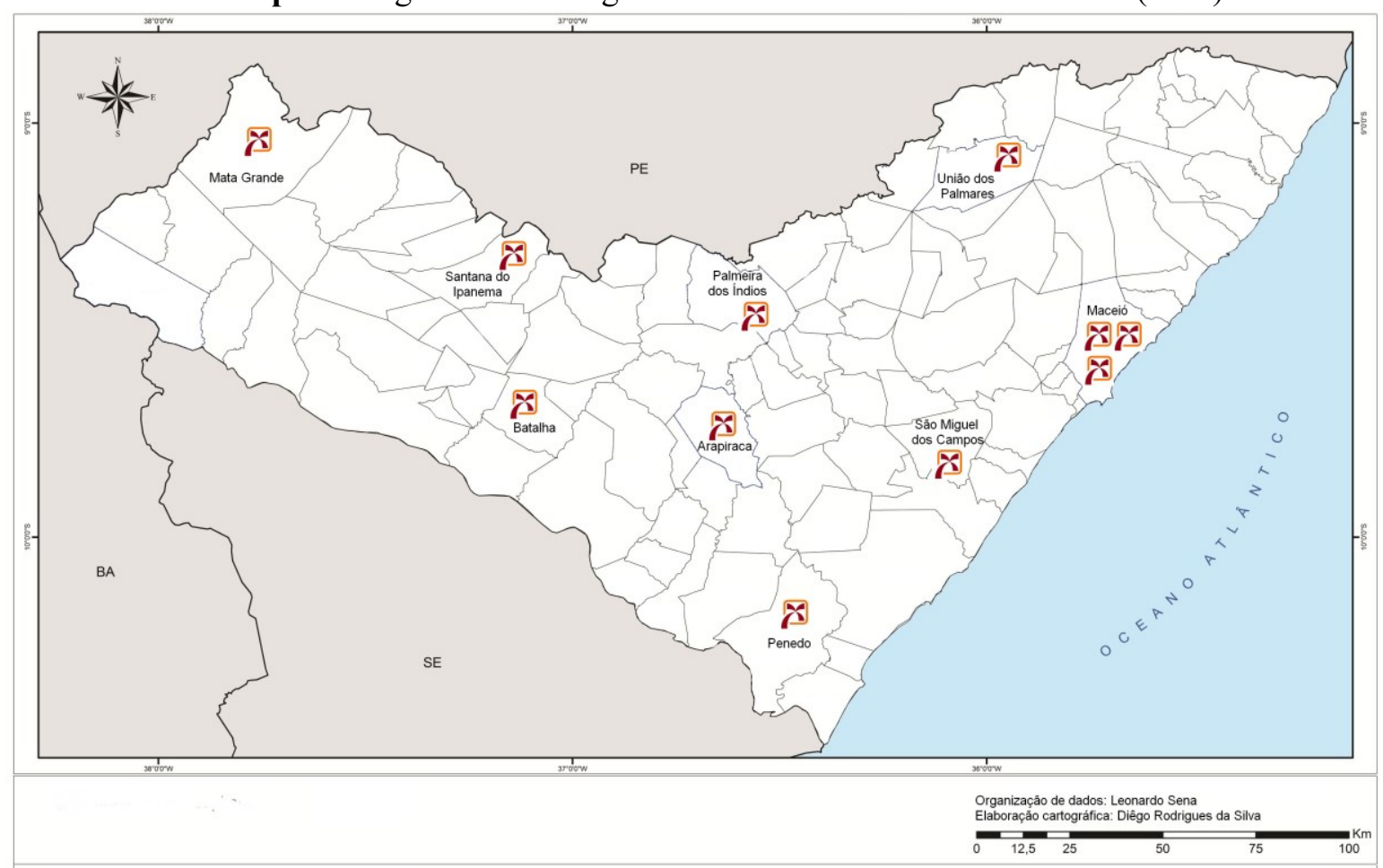

Fonte: BNB, 2012. Organização de dados e elaboração cartográfica: SILVA (2013).

No estado de Alagoas, o BNB teve sua primeira agência instalada em 1954 em Maceió, que concentrava o maior número de empresas do estado. Em 1959 é instalada uma nova unidade na cidade de Arapiraca, segunda maior cidade alagoana e que possui uma localização privilegiada no centro do estado com fácil acesso a vários mercados nas cidades circunvizinhas. No ano seguinte, 1960, é instalada uma nova agência em Mata Grande, localizada no alto sertão conforme previsto nos recursos do Fundo das Secas. Em 1964, a localização de uma nova agência na cidade de Batalha dava continuação ao projeto de desenvolvimento das regiões que integravam o polígono das secas. Nos anos seguintes o BNB buscou reafirmar sua presença em diversas partes do território alagoano, instalando novas agências em quatro cidades importantes do estado que, como foi dito, dispõem de 
um circuito superior parcialmente integrado e exercem uma centralidade em relação a outros municípios do estado. Em 1969 é instalada uma agência na cidade de Penedo. Em 1976 é inaugurada uma nova unidade na cidade de Palmeira dos Índios. No ano de 1979 é instalada uma agência na cidade de União dos Palmares e em 1983 é criada a agência de Santana do Ipanema. No ano de 1991, é instalada na cidade Maceió que abriga quase $1 / 3$ da população do estado, a última unidade fixa do BNB, antes da sua reforma organizacional em 1995.

Desde que deu início ao Programa Agentes de Desenvolvimento, o BNB passou um longo período sem que se interessasse pela abertura de novas agências. Só no ano de 2012, com o crescimento econômico da região Nordeste e o consequente aumento da demanda de crédito, o referido banco demostra uma nova preocupação coma expansão de sua rede de agências. Só no estado de Alagoas estava prevista a criação de cinco novas unidades fixas, que seguem a mesma lógica da difusão do circuito superior no estado. Em 2012, foram inauguradas duas novas agências, uma delas na capital do estado e outra na cidade de São Miguel dos Campos, cuja dinâmica econômica se assemelha com a dos outros centros de zona "A" do estado. Está previsto ainda a abertura de três novas unidades nas cidades de Maragogi, Rio Largo e Delmiro Gouveia. Como foi visto a topologia das agências do BNB obedece a uma lógica que se confunde com a expansão do próprio circuito superior no estado.

O baixo dinamismo econômico de grande parte dos municípios alagoanos, associado aos altos curtos de funcionamento das agências, impede a penetração de uma rede de agências mais espessa no interior do estado. Essa rede aparece ainda mais limitada, considerando que na maior parte dos municípios alagoanos predomina uma população que, de acordo com o Censo Demográfico de 2010 apresentado pelo IBGE, é rural, onde, no território alagoano o circuito superior mantém pouca relação com as atividades locais. Assim, os limites encontrados pelo circuito superior dificultavam a ramificação do Banco do Nordeste no território e impediam que seus serviços alcançassem uma grande parcela de pobres incluídos no seu projeto de desenvolvimento regional.

Os assessores de microcrédito cumprem, portanto, um papel essencial para a expansão da capilaridade bancária da instituição. Isso se deve principalmente ao fato de que a economia da maioria dos municípios do estado é movida pelas atividades do circuito inferior, onde os agentes têm mais facilidade de alcançar, pois depende do deslocamento do cliente até o fixo geográfico. Cada agência dispõe de um número médio de agentes que divulgam e oferecerem seus dois principais programas de crédito, (Crediamigo e Agroamigo) cobrindo um conjunto de cidades na sua área de atuação. Além disso:

Para uma economia precocemente urbanizada, com as características destacadas anteriormente, nenhuma outra intervenção possui tanto potencial para apoiar as iniciativas de empreendedores de pequeno porte que o programa de microcrédito (CARVALHO [2005] 2012, p. 90).

Todavia, o número limitado de assessores de microcrédito em contraste com a grande extensão territorial do mercado, impede que eles articulem a demanda de crédito em todas as comunidades de cada município. Além disso, a falta de conhecimento sobre a realidade local dificulta um direcionamento mais preciso das ações do banco. Como a relação do sistema bancário com as atividades do circuito inferior é baseada muito mais na confiança do que em garantias legais, torna-se muito difícil saber onde aplicar os investimentos. As consequências são o mau direcionamento dos recursos e a insatisfação dos clientes que precisam se adequar às exigências instituídas pelo banco. Por fim, eles acabam não correspondendo às expectativas de retorno econômico, estabelecidas no período da elaboração do projeto.

É por essas razões que o banco, através da figura dos assessores de microcrédito, mantém uma estreita relação com os líderes de associações comunitárias, por meio de reuniões periódicas 
com o objetivo de programar visitas às comunidades que necessitam do crédito. Além disso, o perfil dos clientes, geralmente composto de pessoas com baixo nível de escolaridade, revela bem a dificuldade de lidar com um público historicamente excluído das modernas formas de concessão de crédito, suscitando a intervenção de pessoas que mobilizem e orientem a busca pelos financiamentos. Cada município, assim, abriga diversos agentes de microcrédito não normatizados que residem nas comunidades e intermediam a relação entre a demanda de crédito pré-selecionada e o representante da instituição bancária.

Com a atuação dos agentes de miccrocrédito o BNB no ano de 2011, segundo o relatório de dezembro o BACEN, contando com apenas nove agências, que correspondiam a $6,2 \%$ do total no estado, expandiu a sua capilaridade a todos os municípios alagoanos. Além disso, considerando ainda as limitações da sua estrutura de agências, percebe-se que os números alcançados também revelam uma grande eficiência de suas ações: no estado de Alagoas, o BNB representou 74,6\% das operações de longo prazo e $81,2 \%$ nos financiamentos de crédito rural no estado (BNB, 2011). A atuação dos pastinhas se faz, portanto, indispensável para a expressiva capilaridade das atividades creditícias do BNB no estado, pois permitem a formação de inúmeras artérias, pelas quais o crédito bancário penetra e atinge um grande número de atividades do circuito inferior.

\section{CONSIDERAÇÕES FINAIS}

Ao longo da sua trajetória, o Banco do Nordeste do Brasil caracterizou-se por protagonizar grandes transformações, tanto na sua forma de atuação quanto na dinâmica econômica do próprio Nordeste. Sua missão como agente indutor do desenvolvimento regional refletiu, através do tempo, os objetivos políticos e econômicos do Governo Federal em sintonia com os problemas vivenciados em cada contexto histórico. Tais transformações motivaram diferentes formas de uso do território, que se distinguem desde a busca pelo conhecimento sistematizado da região até o início da década de 1960, à seleção e financiamento de fragmentos do território e setores de atividades estratégicas ao crescimento econômico nordestino até a primeira metade da década de 1990.

A década de 1990 marcou a ocorrência de importantes eventos que motivaram profundas transformações na estrutura do BNB. A livre ação das finanças no território, evidenciada pelas liberalizações normativas do Banco Central do Brasil (BACEN) somada aos avanços técnicos adquiridos nesse período, contribuíram para a criação de novos agentes de crédito, que estenderam sua presença a todos os municípios da região. Evidenciou-se nesta fase, uma estratégia de desenvolvimento voltada, sobretudo, para o financiamento de pequenas atividades econômicas, permitindo uma relação mais intensa e local com o território, desde a sua criação. As dificuldades encontradas nesse período também desencadearam a existência desses agentes de crédito não normatizados, que passaram a ter um papel muito importante na passagem do crédito bancário para o circuito inferior da economia, constituindo um traço de união entre os dois circuitos.

Em Alagoas, a discrepância nos níveis hierárquicos da rede urbana atrelada a seletividade do circuito superior, orientou e constituiu a topologia das agências do BNB no estado. A centralidade exercida por algumas cidades alagoanas em relação as demais permitiu que o aparelho bancário se beneficiasse dos fluxos já existentes entre elas. Todavia, como são as atividades do circuito inferior que predominam na grande maioria dos municípios alagoanos, a ação dos assessores de microcrédito abriu caminho para um novo e complexo mercado. Inaugura-se uma nova estratégia, capaz de alcançar um conjunto atividades não normatizadas que comumente fogem ao sistema bancário tradicional. A atuação dos assessores de microcrédito, contudo, não foi capaz de promover um diálogo que conciliasse as exigências do 
crédito bancário às necessidades de um imenso circuito que buscava adaptar seus mecanismos financeiros a uma forma de organização mais burocrática.

Por fim, verifica-se que a atuação dos agentes de microcrédito tem sido a peça-chave para aproximação do crédito bancário às atividades do circuito inferior. Estes intermediários de crédito articulam os nexos entre o crédito bancário e as atividades não normatizadas, pois combinam os conhecimentos sobre as formas de organização próprias a cada circuito. Percebe-se ainda que a atuação desses agentes, combinada aos programas de microcrédito criados pelo $\mathrm{BNB}$, tem contribuído para uma "hipercapilaridade" (CONTEL, 2011) do crédito no estado. Além disso, seu papel tem provocado um direcionamento mais preciso dos recursos via aparelho bancário e contribuído para uma maior articulação local das atividades do circuito inferior, avivando a dinâmica econômica desses espaços e promovendo, por conseguinte, uma relação mais intensa e local do Banco do Nordeste com o território alagoano.

\section{REFERÊNCIAS}

ARAÚJO, Tânia Bacelar de et al. Celso Furtado, o Nordeste e a Formação do Brasil. In: ALENCAR JÚNIOR, José Sydrião de (Org.). Celso furtado e o Desenvolvimento Regional. Fortaleza: Ed. Banco do Nordeste do Brasil, 2005. p. 209-236.

BANCO DO NORDESTE DO BRASIL. Desempenho operacional e financeiro. Fortaleza: Gabinete da Presidência, 2011.

Relatório anual - 2011. Fortaleza: Ed. Banco do Nordeste do Brasil, 2011.

Relatório anual Agroamigo - 2011. Fortaleza: Ed. Banco do Nordeste do Brasil, 2011.

Relatório anual Crediamigo - 2011. Fortaleza: Ed. Banco do Nordeste do Brasil, 2011.

BINI, Danton Leonel de Camargo; SAMPAIO, Mateus de Almeida Prado. Os Dois Circuitos da Economia Agrícola: o caso do biodiesel. Análise e Indicadores do Agronegócio. São Paulo, SP, v. 4, n. 7, jul. 2009.

BRASIL. Sancionada a lei no 1.649, de 19 de julho de 1952. Cria o Banco do Nordeste do Brasil e dá outras providências. Casa Civil: Subchefia para assuntos jurídicos. Rio de Janeiro, RJ, 19 jul. 1952. Disponível em: <http://www.planalto.gov.br/ccivil_03/leis/1950-1969/L1649.htm>. Acesso em: 9 dez. 2012.

CANO, Wilson. Celso Furtado e a questão regional no Brasil. In: TAVARES, Maria da Conceição (Org.). Celso Furtado e o Brasil. São Paulo: Fundação Perseu Abramo, 2000.

CARDOSO, Gil Célio de Castro. O Estado Desenvolvimentista e o Nordeste: o BNB na busca de um novo modelo de desenvolvimento regional. 2006. Tese (Doutorado em Ciências Sociais) - Centro de Ciências Humanas, Letras e Artes, Universidade Federal do Rio Grande do Norte, Natal, 2006.

CARVALHO, Cícero Péricles de. Economia Popular: uma via de modernização para Alagoas. 4 ed. Maceió: EDUFAL, [2006] 2012.

CONTEL, Fabio Betioli. Território e finanças: técnicas, normas e topologias bancárias no Brasil. São Paulo: Anablume, 2011.

FURTADO, Celso. Formação econômica do Brasil. 27. ed. São Paulo: Companhia Editora Nacional: Publifolha, [1959] 2000.

INSTITUTO BRASILEIRO DE GEOGRAFIA E ESTATÍSTICA. Censo Demográfico 2010. Disponível em: $<$ http://www.censo2010.ibge.gov.br/>. Acesso em 12 set. 2012.

Regiões de Influência das cidades 2007. 1 mapa, color. Escala 1: 100.000. Disponível em: $\overline{<h t t p: / / w w w . i b g e . g o v . b r / h o m e / g e o c i e n c i a s / g e o g r a f i a / r e g i c . s h t m>. ~ A c e s s o ~ e m: ~} 25$ nov. 2012.

OLIVEIRA, Clonilo Moreira Sindeaux de; VIANNA, Pedro Jorge Ramos. Desenvolvimento regional: 50 anos do BNB. Fortaleza: Ed. Banco do Nordeste, 2005. 
OLIVEIRA, Francisco de. Elegia para uma re(li)gião: Sudene, Nordeste. Planejamento e conflito de classes. 3. ed. Rio de Janeiro: Paz e Terra, [1977] 1981.

SANTOS, Arnaldo; GOIS, Francisco F. de. Banco do Nordeste: 60 anos de história e desenvolvimento. Fortaleza: Premius, 2012.

SANTOS, Milton; SILVEIRA, María Laura. O Brasil: território e sociedade no início do século XXI. Rio de Janeiro: Record, [2001] 2006.

Espaço e método. 5. ed. São Paulo: EDUSP, [1985] 2008.

O espaço dividido: os dois circuitos da economia urbana dos países subdesenvolvidos. Tradução Myrna T. Rego Viana. 2. ed. 1 reimpr. São Paulo: EDUSP, [1975] 2008.

. A natureza do espaço: técnica e tempo, razão e emoção. 4 ed. São Paulo: EDUSP, [1996] 2009.

TAVARES, Maria da Conceição. Da substituição de importações ao capitalismo financeiro. 9. ed. Rio de Janeiro: Zahar Editores, [1972] 1981.

\section{Sites consultados:}

$<$ http://www.bnb.gov.br>. BANCO DO NORDESTE DO BRASIL - BNB. Acesso em: 15 jan. 2013.

$<$ http://www.bcb.gov.br>. BANCO CENTRAL DO BRASIL - BCB. Acesso em: 02 fev. 2013.

$<$ http://www.febraban.org.br>. FEDERAÇÃO BRASILEIRA DE BANCOS - FEBRABAN. Acesso em: 07 nov. 2012.

$<$ http://www.ibge.gov.br>. INSTITUTO BRASILEIRO DE GEOGRAFIA E ESTATÍSTICA IBGE. Acesso em: 06 fev. 2013.

Notas: 